\title{
Cutaneous Venous Malformations in Familial Cerebral Cavernomatosis Caused by KRIT1 Gene Mutations
}

\author{
Agustí Toll $^{a}$ Elisabet Parera ${ }^{a}$ Ana M. Giménez-Arnau ${ }^{a} \quad$ Alejandro Pou $^{b}$ \\ Josep Lloretac Nisha Limaye ${ }^{d}$ Miikka Vikkulad Ramon M. Pujola \\ Departments of a Dermatology, ${ }^{\mathrm{b}}$ Neurology, and ${ }^{\mathrm{C} P a t h o l o g y, ~ H o s p i t a l ~ d e l ~ M a r, ~ I M A S, ~ B a r c e l o n a, ~ S p a i n ; ~}$ \\ dLaboratory of Human Molecular Genetics, de Duve Institute, Université catholique de Louvain, Brussels, Belgium
}

\section{Key Words}

Cutaneous venous malformation - Cerebral cavernomatosis . KRIT1 gene mutation

\begin{abstract}
Background: Cerebral cavernous malformations (CCMs) are vascular lesions characterized by abnormally enlarged capillary cavities without intervening brain parenchyma. Although often asymptomatic, seizures, cerebral haemorrhages and focal neurological deficits are well-documented complications. Mutations in the CCM1 (7q21-22), CCM2 (7p13-15) and CCM3 (3q25.2-27) genes have been identified in familial CCM. In rare instances, the association of congenital hyperkeratotic cutaneous capillary-venous malformations (HCCVMs) with CCM1 has been reported. Observations: We studied 6 members of a family with CCMs. Four members of the family developed late-onset multiple, tiny, bluish, soft, cutaneous papules, mainly located on the face, arm and abdominal area, corresponding histologically to venous malformations. A splice donor site mutation in intron 4 (c. $1146+1 \mathrm{G} \rightarrow \mathrm{A}$ ) in the CCM1 gene was identified. Conclusions: Our findings suggest that mutations in the KRIT1 gene may cause phenotypically heterogeneous cutaneous vascular lesions other than those previously described as HCCVMs.

Copyright $\odot 2009$ S. Karger AG, Basel
\end{abstract}

\section{Introduction}

Cavernomas or cerebral cavernous malformations (CCMs) are fairly common (0.5\%) vascular lesions involving the central nervous system (CNS) characterized by abnormally dilated capillary beds lined by a single layer of endothelium without intervening neural structures. The lesions may be solitary or multiple. Although often asymptomatic, $20-30 \%$ of individuals may experience symptoms including seizures, headaches, stroke or haemorrhage, making CCMs potentially fatal lesions.

Patients with CCM may develop vascular malformations in a wide range of anatomical areas other than the CNS, such as vertebrae [1], retina [2] and skin [1, 3, 4]. Both cerebral and extracerebral lesions show similar histological findings, consisting of malformed capillary and venous-like channels.

CCMs may occur either as a sporadic process or as a familial disorder with an autosomal dominant pattern of inheritance (10-20\% of cases). Genetic linkage to 3 chromosomal loci, 3q25.2-27, 7p13-15 and 7q21-22, has been detected, and mutations in the CCM1 gene (located on 7q21-22), which encodes a KRIT1 protein (acronym for the Krev Interaction Trapped 1 gene), as well as the CCM2 (encoding MGC4607) and CCM3 (encoding PDCD10)

\section{KARGER}

Fax +41613061234 E-Mail karger@karger.ch www.karger.com
Agustí Toll

Department of Dermatology

Hospital del Mar, IMAS

ES-08003 Barcelona (Spain)

Tel. +34932483 380, Fax +34932483 328, E-Mail 93828@imas.imim.es 
Table 1. Clinical, pathological and radiological findings

\begin{tabular}{|c|c|c|c|c|c|c|}
\hline $\begin{array}{l}\text { Case/age/ } \\
\text { gender }\end{array}$ & Cutaneous manifestations & $\begin{array}{l}\text { Histopatholog- } \\
\text { ical samples }\end{array}$ & $\begin{array}{l}\text { Neurological } \\
\text { manifestations }\end{array}$ & Neuroradiological studies (MRI) & Outcome & $\begin{array}{l}\text { Genetic } \\
\text { studies }\end{array}$ \\
\hline $1 / 85 / \mathrm{F}$ & $\begin{array}{l}\text { Five violaceous papules on } \\
\text { malar areas }\end{array}$ & NA & None & $\begin{array}{l}\text { Hypo-intense images distributed in } \\
\text { both cerebral hemispheres, brain stem } \\
\text { and cerebellum (aged 75) }\end{array}$ & Alive & Yes \\
\hline $2 / 80 / \mathrm{F}$ & $\begin{array}{l}\text { Four violaceous papules on } \\
\text { malar areas }\end{array}$ & NA & None & NA & $\begin{array}{l}\text { Death (IC } \\
\text { haemorrhage) }\end{array}$ & NA \\
\hline $3 / 54 / \mathrm{M}$ & $\begin{array}{l}\text { Five violaceous papules on } \\
\text { malar areas, } 1 \text { violaceous } \\
\text { papule on the epigastria and } \\
3 \text { subcutaneous nodules on } \\
\text { the left leg }\end{array}$ & $\begin{array}{l}\text { Yes } \\
\text { (cutaneous) }\end{array}$ & $\begin{array}{l}\text { Locked-in syndrome } \\
\text { (aged 32); right sixth- } \\
\text { nerve palsy and } \\
\text { contralateral body } \\
\text { hyperaesthesia }\end{array}$ & $\begin{array}{l}\text { Hypo-intense images with central } \\
\text { hyperintensity in the left parietal region } \\
\text { and right protuberance (aged } 42 \text { ) }\end{array}$ & Alive & Yes \\
\hline $4 / 49 / \mathrm{M}$ & $\begin{array}{l}\text { Ten violaceous papules in } \\
\text { malar areas and } 1 \text { on the } \\
\text { arm }\end{array}$ & $\begin{array}{l}\text { Yes } \\
\text { (cutaneous) }\end{array}$ & No symptoms & $\begin{array}{l}\text { Hypo-intense images with central } \\
\text { hyperintensity located in the subcortical } \\
\text { right parieto-occipital, left thalamic and } \\
\text { right protuberance areas (aged 49) }\end{array}$ & $\begin{array}{l}\text { Death (IC } \\
\text { haemorrhage) }\end{array}$ & NA \\
\hline $5 / 37 / \mathrm{M}$ & NA & Yes (cerebral) & NA & NA & $\begin{array}{l}\text { Death (IC } \\
\text { haemorrhage) }\end{array}$ & NA \\
\hline $6 / 53 / \mathrm{F}$ & None & NA & None & Normal cerebral CT & Alive & Yes \\
\hline
\end{tabular}

IC $=$ Intracerebral; NA = not available.

genes have been identified, including frameshift, nonsense and missense mutations, as well as splice junction mutations [5-7]. These proteins seem to be involved in both angiogenesis and vascular remodelling [8].

The development of hyperkeratotic cutaneous capillary-venous malformations (HCCVMs; MIM 116860) has been reported in families harbouring KRIT1 mutations $[3,4]$.

We describe a family whose members showed coexisting CCM and cutaneous venous malformations. We identified a mutation in the CCM1 gene in 3 members of this family. These findings suggest that mutations in the KRIT1 gene may cause phenotypically heterogeneous cutaneous vascular lesions, differing from those previously described as HCCVMs.

\section{Material and Methods}

\section{Patients}

A kindred with CCMs and cutaneous vascular malformations segregating over 3 generations in an autosomal dominant manner was evaluated (fig. 1). Clinical, neuroradiological (MRI and gradient echo sequences) and/or pathological (biopsies from cutaneous and cerebral tissue) features were available for 6 members. A thorough cutaneous and mucosal examination for vascular

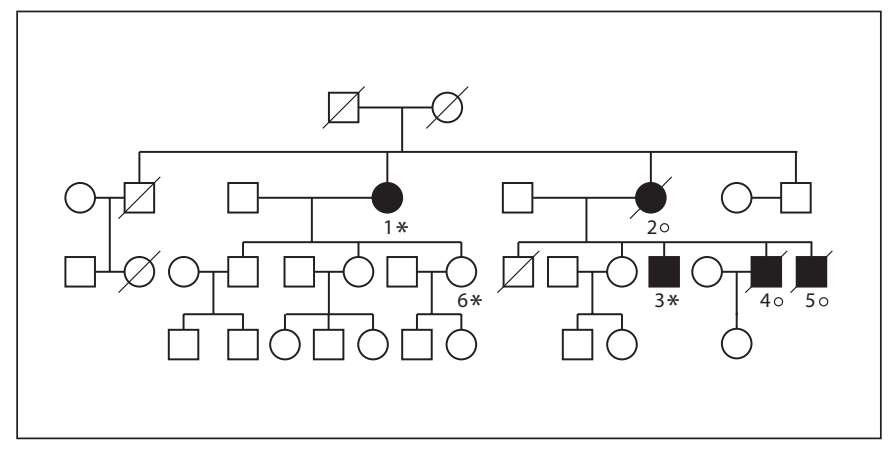

Fig. 1. Pedigree of the present family. Filled symbols = Cutaneous and cerebral lesions; open symbols = not known to be affected; asterisk = patients showing the mutation in KRIT1; open circle = no genetic studies available; slash $=$ deceased.

lesions was performed in 5 members of the family (cases $1-4$ and 6).

A signed informed consent was obtained from those wanting to participate in the genetic study, as approved by the ethics committee of the Medical Faculty of the Université catholique de Louvain, Brussels, Belgium. Blood samples were collected for individuals 1, 3 and 6. Genomic DNA was extracted from buffy coats using the Qiagen DNA purification kit (Westburg, The Netherlands). 
Fig. 2. Patients 3 and 4 showing multiple, tiny, bluish papules in the left malar areas.


Mutation Analysis of the KRIT1 Gene

All 20 transcribed exons of the KRIT1 gene, including exonintron boundaries, were amplified by PCR using genomic DNA as template. Primer sequences and cycling conditions were performed as previously reported [3, 9]. Amplified products were screened by denaturing high-performance liquid chromatography using the Wave $3500 \mathrm{HT}$ system (Transgenomic Inc., Omaha, Nebr., USA). The fragments showing abnormal migration patterns were further characterized by direct cycle sequencing, using a Beckam CEQ2000 capillary sequencer (Analis, Belgium).

\section{Results}

The results are summarized in table 1. Five individuals presented cutaneous and/or neurological manifestations. Cases 1-4 showed cutaneous vascular lesions. Two individuals with cutaneous involvement also manifested concurrent cerebral complications (cases 3 and 4). One patient (case 5) had a fatal outcome due to intracerebral haemorrhage in 1985, and no dermatological exploration could be performed.

\section{Cutaneous Clinical Manifestations}

Cutaneous physical examination revealed multiple, tiny, bluish, easily depressible papules in the malar area in 4 patients (cases 1,2, 3 and 4). Four to 10 bluish bilateral papules measuring 2-3 $\mathrm{mm}$ were noted in these areas (fig. 2). Patients 3 and 4 showed similar individual lesions in the upper abdominal region and on the arm, respectively. Patient 4 also had a bluish papule measur-
Fig. 3. MRI examination from patient 1 showing cerebral hypointense images corresponding to cavernomas.

ing $5 \mathrm{~mm}$ in diameter on the lower lip suggestive of venous-lake angioma (fig. 2b). The diagnosis of blue rubber bleb naevus syndrome (BRBNS) was clinically suspected. These lesions were strikingly subtle, and the patients had not seeked medical advice for them. Patient 3 also complained of 3 asymptomatic subcutaneous nodules measuring $1.5 \mathrm{~cm}$ on the left leg. Patient 6 had not developed cutaneous manifestations at the age of 60. 


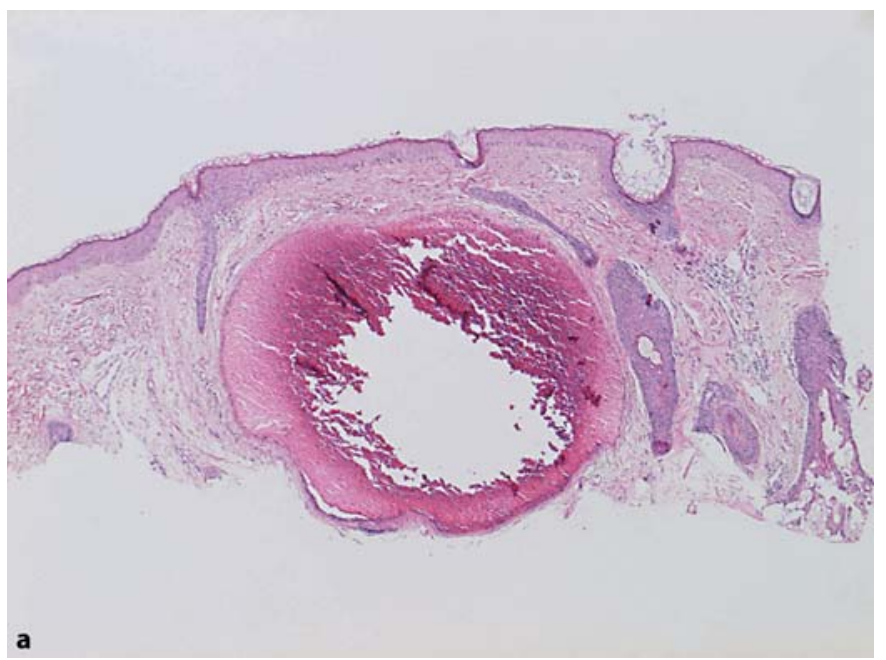

Fig. 4. a Histology of a facial lesion from patient 4 showing a single large dilated vascular channel with a flat endothelial lining in the upper dermis. Haematoxylin-eosin stain. $\times 40$. b Histology of a vascular lesion on the arm from patient 4 . Haematoxylin-eosin stain. $\times 40$. c Histology of a post-mortem brain sample (patient 5) showing a juxtaposition of dilated vascular structures lined by a single layer of endothelial cells and collagen. Haematoxylin-eosin stain. $\times 100$.

\section{Neurological Clinical Manifestations}

Patient 3 had suffered a subacute bleeding in the protuberance that resulted in a long-term locked-in syndrome at the age of 32 that progressively improved in the following years. At present, this patient suffers from a right sixth-nerve palsy and a contralateral hypo-aesthesia. Patient 4 died at the age of 49 due to progressive bleeding from a brain cavernoma. Patient 5 died in 1985 at the age of 37 due to postsurgical complications of a growing cavernoma of the left cerebral hemisphere.

\section{Neuroradiological Studies}

Three patients (patients 1, 3 and 4) underwent axial $\mathrm{T}_{2}$-weighted gradient echo sequence MRI examinations. These studies revealed multiple hypo-intense images,
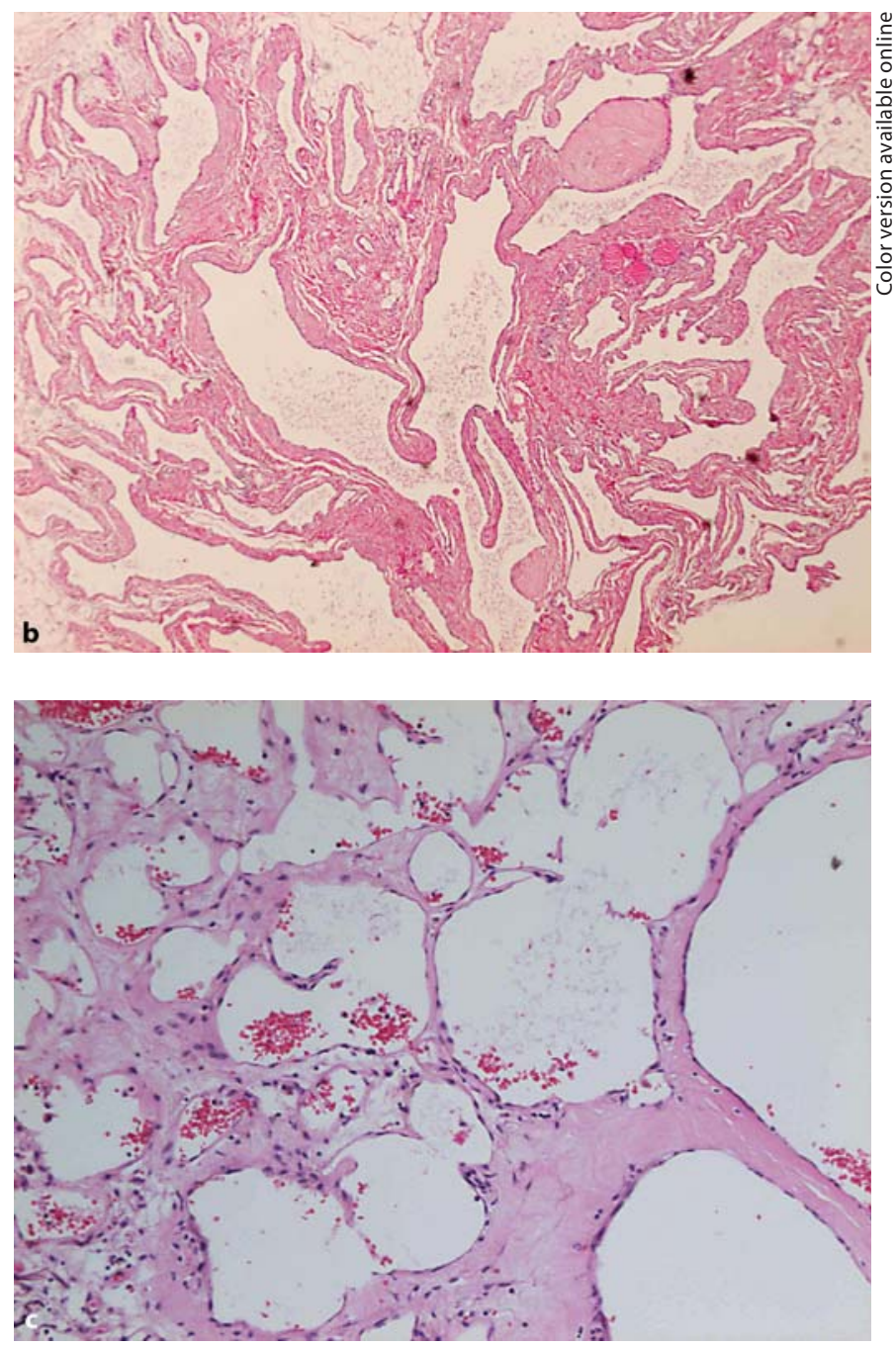

suggestive of cavernous angiomas in all patients (fig. 3). The lesions were located in both cerebral hemispheres, the cerebellum or the thalamic and/or protuberance region (table 1).

\section{Histopathological Findings}

Skin biopsies of 2 papules on the face (patients 3 and 4) and on the arm (patient 4) were performed. Two different histological patterns were observed (fig. 4). The facial lesions showed a single large dilated vascular channel with a flat endothelial lining in the upper dermis consistent with a venous lake (fig. $4 \mathrm{a}$ ). The lesion on the arm also had a deeper component, with dilated vascular structures affecting the subcutaneous fat (fig. 4b), and closely resembled the changes observed in a cerebral tis- 
sue sample (fig. 4c). The deep lesion on the leg from patient 3 was not biopsied. Immunohistochemical studies showed positive staining for CD34 and smooth-muscle actin, but negativity for elastic fibres, desmin and CD23 stainings. These findings were consistent with venous malformations.

A post-mortem brain sample from a cerebral lesion (patient 5) showed a juxtaposition of dilated vascular structures lined by a single layer of endothelial cells and collagen without intervening brain parenchyma (fig. 4c).

\section{Genetic Findings}

Mutational screening of DNA of individuals 1, 3 and 6 resulted in the identification of a heterozygous nucleotide change in the intron four $5^{\prime}$ donor splice site sequence (c. $1146+1 \mathrm{G} \rightarrow \mathrm{A}$ ) that disrupts the invariant splice donor site from $g t$ to $a t$ in all of them. Allele-specific PCR screening confirmed the sequencing results for all patients. Consensus splice site substitution is commonly related to exonic splicing defects, but as no lymphoblasts were available, this could not be tested.

\section{Discussion}

Isolated reports of 'cherry angiomas' [10], 'cutaneous bluish nodules' [11], capillary vascular anomalies [12], cavernous 'angiomas' [13] and angiokeratoma-like lesions [14] have been reported in patients with multiple CCM or belonging to families with multiple cavernomas. However, histological data were only rarely available [14], and genetic studies have rarely been performed in patients presenting this association.

Isolated observations of CCM1 gene mutations in patients with CCMs and cutaneous lesions have been reported $[1,3]$. These cutaneous lesions share similar clinical and histological features and have been termed HCCVMs [15]. HCCVM lesions are described as congenital crimson-coloured or red-to-purple, irregularly shaped macules, plaques or patches, which can extend to several centimetres. Crimson-coloured tiny papules $(3-10 \mathrm{~mm})$ with a hyperkeratotic epidermis have also been reported $[15,16]$. They may appear on the limbs, buttocks and forearms $[1,3,15]$.

Labauge et al. [15] studied 4 families (10 individuals) with CCMs who showed congenital, single lesions localized on the lower limbs in 9 patients and on the arm in 1 . These lesions were crimson-coloured tiny papules (3$10 \mathrm{~mm})$ or larger macules $(20-65 \mathrm{~mm})$ with a hyper- keratotic epidermis. The histology, available in 4 patients, revealed orthokeratosis and hyperkeratosis, abundant dilated capillaries, and blood-filled spaces in papillary and reticular dermis extending to the hypodermis.

Eerola et al. [3] demonstrated mutations in the KRIT1 gene in 2 patients with HCCVM. They found a deletion of $\mathrm{G}$ in the first exon of the KRIT1 gene (KRIT1 $\left.\Delta^{\mathrm{G} 103}\right)$. No mutations in exon 1 had been previously described in patients with CCMs so that they hypothesized that an earlier truncation of the KRIT1 gene could have triggered the cutaneous manifestations.

In 2002, Chen et al. [17] reported a family of Chinese origin with CCM and a mutation in exon 19 in the CCM1 gene. A male member of this family developed cutaneous lesions on both forearms and right cheek at the age of 67 . These vascular lesions were purple-black, round, raised, non-tender, 2-10 $\mathrm{mm}$ in diameter, resembling our patients' lesions. However, the patient also showed a flat reddish discolouration surrounding the angioma-like lesions. A skin biopsy was not performed. Four other members of the family developed cerebral manifestations without skin lesions.

Clatterbuck et al. [1] reported a 53-year-old woman with CCMs and a red-to-purple large patch and nodules ranging in size from 2 to $4 \mathrm{~mm}$ prior to treatment with laser. Microscopic examination showed multiple, endothelium-lined vascular channels in the dermis and hypodermis. Clatterbuck et al. described a tandem duplication 1487-1497 in exon 4 of KRIT1 in this patient.

In contrast to HCCVMs, our patients presented acquired, multiple, tiny, non-confluent bluish papules, mainly located on the face, and clinically suggesting the diagnosis of venous lakes or BRBNS. No signs or symptoms of gastro-intestinal involvement were present. As far as we are concerned, venous malformations clinically suggesting BRBNS or venous lakes secondary to KRIT1 mutations have not been reported previously.

Taking into account the similarities between the lesions observed in our patients and those observed in BRBNS, a possible relationship between both disorders may be suggested. Interestingly, sporadic BRBNS patients developing symptomatic cerebral and/or spinal vascular lesions have occasionally been described [18-20]. Although some authors have suggested that BRBNS and the familial venous malformation syndrome, caused by mutation in the TIE gene (9p21; MIM 600221), are the same condition, the underlying genetic mechanism responsible for BRBNS is not established (MIM 600195) [21]. A possible role of KRIT1 gene mutations could be hypoth- 
esized. In a recent report, Chen et al. [17] ruled out CCM1 mutations in an 80-year-old man with multiple bilateral CNS cavernous angiomas and multiple, small, bluish, soft, non-tender skin lumps consistent with the BRBNS [20].

Loss of KRIT1 protein function due to gene mutations could be explained by haplo-insufficiency or a two-hit model. The clinical phenotype of multiple lesions in familial cases and single lesions in sporadic cases, the preponderance of nonsense mutations and the structure of the protein suggest that CCMs may be caused by somatic mutations of the remaining functional gene (two-hit model) in familial cases in a tumour-suppressor-like mechanism. Some patients with CCMs harbour segmental manifestations, which would also support a two-hit model [1], as already observed for glomuvenous malformation, another cutaneous vascular anomaly [22]. In our opinion, the observation of patients who progressively develop skin lesions during adulthood would also be consistent with loss of function of KRIT1 and a two-hit model of the disease.

The single base pair transition at the exon-intron border in intron 4 (previous nomenclature: IVS $4+1 \mathrm{G} \rightarrow \mathrm{A}$; now: c. $1146+1 \mathrm{G} \rightarrow \mathrm{A}$ ) was previously reported by Sahoo et al. [23] in a study that allowed the identification of KRIT1 as the CCM1 gene. This mutation was found in a non-Hispanic Caucasian family showing CCM lesions. Coincident with patient 6 from our study, no cutaneous lesions were reported in any of the families included in the study by Sahoo et al. These findings underline the heterogeneous clinical manifestations associated with KRIT1 mutations and would also support the hypothesis of a second-hit model.

In conclusion, KRIT1 gene mutations may cause heterogeneous vascular skin lesions including non-hyperkeratotic acquired lesions. CCM should be suspected in patients with a familial history of neurological anomalies who also develop multiple, tiny, cutaneous venous lesions. An early diagnosis of familial cases with this condition is of great importance as it may cause severe CNS manifestations that may be amenable to surgical correction.

\section{Acknowledgements}

We are grateful to all the family members for their invaluable contributions. These studies were partially supported by the Interuniversity Attraction Poles initiated by the Belgian Federal Science Policy, network 5/25; and 6/05; Concerted Research Actions (A.R.C.) - Convention No 02/07/276 and No 07/12-005 of the Belgian French Community Ministry; the National Institute of Health, Program Project P01 AR48564; EU FW6 Integrated project LYMPHANGIOGENOMICS, LSHG-CT-2004-503573; and the F.R.S.-FNRS (Fonds de la recherche scientifique) (all to M.V., a 'Maître de recherches du F.R.S.-FNRS').

\section{References}

1 Clatterbuck RE, Cohen B, Gailloud P, Murphy K, Rigamonti D: Vertebral hemangiomas associated with familial cerebral cavernous malformation: segmental disease expression. Case report. Neurosurgery 2002; 97:227-230.

-2 Dobyns WB, Michels VV, Groover RV, Mokri B, Trautmann JC, Forbes GS, Laws ER Jr: Familial cavernous malformations of the central nervous system and retina. Ann Neurol 1987;21:578-583.

-3 Eerola I, Plate KH, Spiegel R, Boon LM, Mulliken JB, Vikkula M: KRIT1 is mutated in hyperkeratotic cutaneous capillary-venous malformation associated with cerebral capillary malformation. Hum Mol Genet 2000; 9:1351-1355.

-4 Denier C, Labauge P, Brunereau L, Cavé-Riant F, Marchelli F, Arnoult M, Cecillon M, Maciazek J, Joutel A, Tournier-Lasserve E: Clinical features of cerebral cavernous malformations patients with KRIT1 mutations. Ann Neurol 2004;55:213-220.
5 Craig HD, Günel M, Cepeda O, Johnson EW, Ptacek L, Steinberg GK, Ogilvy CS, Berg MJ, Crawford SC, Scott RM, Steichen-Gersdorf E, Sabroe R, Kennedy CT, Mettler G, Beis MJ, Fryer A, Awad IA, Lifton RP: Multilocus linkage identifies two new loci for a mendelian form of stroke, cerebral cavernous malformation, at 7p15-13 and 3q25.2-27. Hum Mol Genet 1998;7:1851-1858.

-6 Bergametti F, Denier C, Labauge P, Arnoult $\mathrm{M}$, Boetto S, Clanet M, Coubes P, Echenne B, Ibrahim R, Irthum B, Jacquet G, Lonjon M, Moreau JJ, Neau JP, Parker F, Tremoulet M, Tournier-Lasserve E: Mutations within the programmed cell death 10 gene cause cerebral cavernous malformations. Am J Hum Genet 2005;76:42-51.

-7 Revencu N, Vikkula M: Cerebral cavernous malformation: new molecular and clinical insights. J Med Genet 2006;43:716-721.

$\checkmark 8$ Seker A, Pricola KL, Guclu B, Ozturk AK, Louvi A, Gunel M: CCM2 expression parallels that of CCM1. Stroke 2006;37:518-523.
9 Eerola I, McIntyre B, Vikkula M: Identification of eight novel 5'-exons in cerebral capillary malformation gene-1 (CCM1) encoding KRIT1. Biochim Biophys Acta 2001;1517: 464-467.

10 Gass JD: Cavernous hemangioma of the retina: a neuro-oculo-cutaneous syndrome. Am J Ophthalmol 1971;71:799-814.

11 Bartolomei F, Lemarquis P, Alicherif A, Lepillouer-Prost A, Sayag J, Khalil R: Systematized cavernous angiomatosis with multiple cerebral and cutaneous localizations. Rev Neurol (Paris) 1992;148:568-570.

12 Goldberg RE, Pheasant TR, Shields JA: Cavernous hemangioma of the retina: a fourgeneration pedigree with neurocutaneous manifestations and an example of bilateral retinal involvement. Arch Ophthalmol 1979; 97:2321-2324.

13 Filling-Katz MR, Levin SW, Patronas NJ, Katz NN: Terminal transverse limb defects associated with familial cavernous angiomatosis. J Med Genet 1992;42:346-351.
Toll/Parera/Giménez-Arnau/Pou/ Lloreta/Limaye/Vikkula/Pujol 
14 Ostlere L, Hart Y, Misch KJ: Cutaneous and cerebral haemangiomas associated with eruptive angiokeratomas. $\mathrm{Br} \mathrm{J}$ Dermatol 1996;135:98-101.

- 15 Labauge P, Enjolras O, Bonerandi J-J, Laberge S, Dandurand M, Joujoux JM, Tournier-Lasserve E: An association between autosomal dominant cerebral cavernomas and a distinctive hyperkeratotic cutaneous vascular malformation in four families. Ann Neurol 1999;45:250-254.

16 Zlotoff BJ, Bang RH, Padilla RS, Morrison L: Cutaneous angiokeratoma and venous malformations in a Hispanic-American patient with cerebral cavernous malformations. Br J Dermatol 2007;157:210-212.

$\checkmark 17$ Chen DH, Lipe HP, Qin Z, Bird TD: Cerebral cavernous malformation: novel mutation in a Chinese family and evidence for heterogeneity. J Neurol Sci 2002;196:91-96.
18 Waybright EA, Selhorst JB, Rosenblum WI, Suter CG: Blue rubber bleb nevus syndrome with CNS involvement and thrombosis of a vein of Galen malformation. Ann Neurol 1978;3:464-467.

19 Satya-Murti S, Navada S, Eames F: Central nervous system involvement in the blue rubber bleb nevus syndrome. Arch Neurol 1986, 43:1184-1186.

20 Vig EK, Brodkin KI, Raugi GJ, Gladstone H: Blue rubber bleb nevus syndrome in a patient with ataxia and dementia. J Geriatr Psychiatry Neurol 2002;15:7-11.

21 Gallione CJ, Pasyk KA, Boon LM, Lennon F, Johnson DW, Helmbold EA, Markel DS, Vikkula M, Mulliken JB, Warman ML, et al: A gene for familial venous malformations maps to chromosome $9 \mathrm{p}$ in a second large kindred. J Med Genet 1995;32:197-199.
22 Brouillard P, Boon LM, Mulliken JB, Enjolras $\mathrm{O}$, Ghassibé $\mathrm{M}$, Warman $\mathrm{ML}$, Tan OT, Olsen BR, Vikkula M: Mutations in a novel factor, glomulin, are responsible for glomuvenous malformations ('glomangiomas'). Am J Hum Genet 2002;70:866-874.

23 Sahoo T, Johnson EW, Thomas JW, Kuehl PM, Jones TL, Dokken CG, Touchman JW, Gallione CJ, Lee-Lin SQ, Kosofsky B, Kurth JH, Louis DN, Mettler G, Morrison L, GilNagel A, Rich SS, Zabramski JM, Boguski MS, Green ED, Marchuk DA: Mutations in the gene encoding KRIT, a Krev-1/rapla binding protein, cause cerebral cavernous malformation (CCM1). Hum Mol Genet 1999;8:2325-2333. 